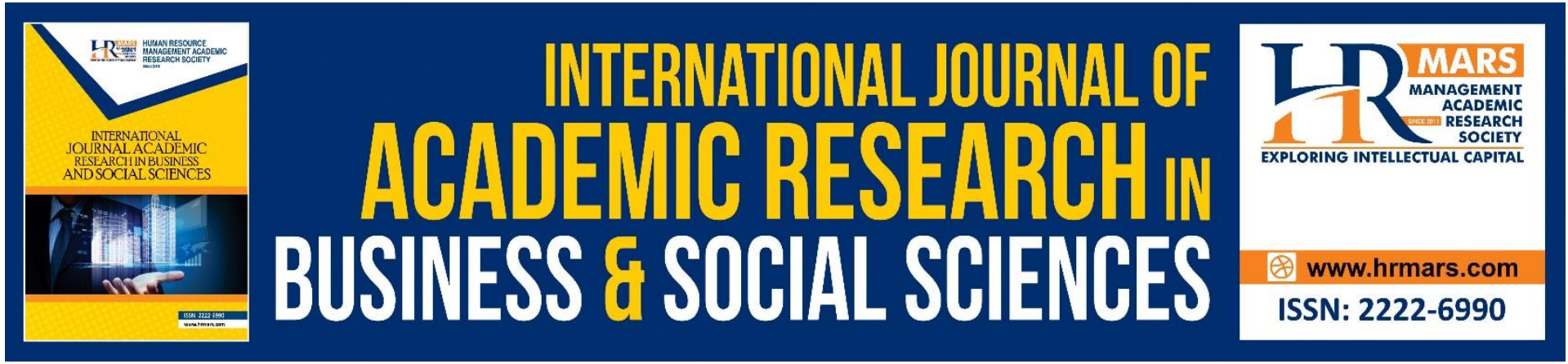

\title{
The Readiness for Independent Living among Incarcerated Adolescents in Malaysia: A Conceptual Paper
}

Thiresyinie Tamil Chelvam, Mohd Najmi Daud, Mohamad Naqiuddin Dahamat Azam

To Link this Article: http://dx.doi.org/10.6007/IJARBSS/v11-i9/10849

DOI:10.6007/IJARBSS/v11-i9/10849

Received: 16 July 2021, Revised: 20 August 2021, Accepted: 28 August 2021

Published Online: 14 September 2021

In-Text Citation: (Chelvam et al., 2021)

To Cite this Article: Chelvam, T. T., Daud, M. N., \& Azam, M. N. D. (2021). The Readiness for Independent Living among Incarcerated Adolescents in Malaysia: A Conceptual Paper. International Journal of Academic Research in Business and Social Sciences, 11(9), 1159-1168.

Copyright: () 2021 The Author(s)

Published by Human Resource Management Academic Research Society (www.hrmars.com)

This article is published under the Creative Commons Attribution (CC BY 4.0) license. Anyone may reproduce, distribute, translate and create derivative works of this article (for both commercial and non-commercial purposes), subject to full attribution to the original publication and authors. The full terms of this license may be seen at: http://creativecommons.org/licences/by/4.0/legalcode

Vol. 11, No. 9, 2021, Pg. 1159 - 1168

Full Terms \& Conditions of access and use can be found at http://hrmars.com/index.php/pages/detail/publication-ethics 


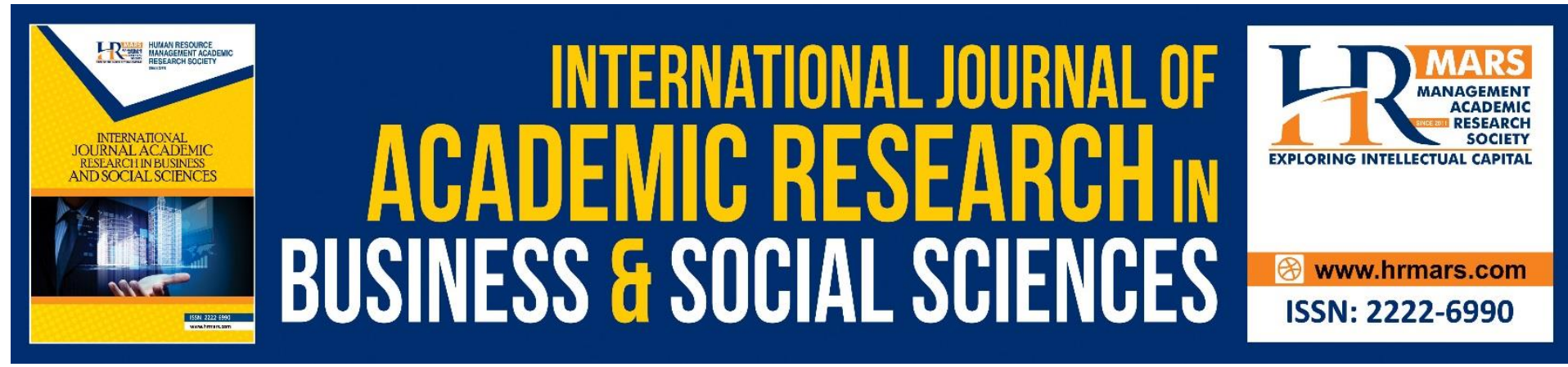

\title{
The Readiness for Independent Living among Incarcerated Adolescents in Malaysia: A Conceptual Paper
}

\author{
Thiresyinie Tamil Chelvam, Mohd Najmi Daud, Mohamad \\ Naqiuddin Dahamat Azam \\ Department of Human Development and Family Studies, Faculty of Human Ecology, \\ Universiti Putra Malaysia, 43400 Serdang, Selangor, Malaysia \\ Email: thiresyinietamil@gmail.com
}

\begin{abstract}
Each year thousands of adolescents are discharged from incarceration across the nation. The Prison Department, Malaysia shows up that most of the adolescents who were released from the incarceration period infringe again and re-entered the rehabilitation centre. The increasing number of juvenile crimes and the escalating number of adolescents with repeated offences have challenged the effectiveness of existing intervention procedures and policies. By far, the intervention programs implemented at the approved school in Malaysia are mostly based on 'one for all' orientation. All inmates have to go through the same intervention process through this practice regardless of their different cases and background. Yet, little is known on how well incarcerated adolescents are equipped with relevant knowledge and skills to ensure their readiness to integrate with the outside social world upon their release from the approved schools. Given that, their readiness to cope and adapt with their lives upon their release remains elusive. Therefore, the present paper seeks to analyze the strengths and limitations of the existing intervention programs at approved schools in Malaysia. Also, factors contributing to incarcerated adolescents' readiness to reintegrate with society and to live independently, namely, coping resources of his/her needs of support, information, and feedback to delineate the challenges lying ahead, are scrutinized and proposed to improve the existing practices.
\end{abstract}

Keywords: Incarcerated Adolescents, Coping Resources, Readiness for Independent Living, Intervention, Tunas Bakti School

\section{Introduction}

Worldwide research studies have indicated that every year there are thousands of incarcerated adolescents leave rehabilitation care to move towards independent life (Wade, 2008). However, the concept of independence is often imbued with feelings of fear, abandonment and dilemma, leading them to the wrong path over and over (Mayock, 2008). Circumstances like the absence of supportive networks have contributed to the increased number of repeated offences among Malaysian juveniles by $37.5 \%$, from 491 cases in 2017 to 675 cases in 2018. These statistics show that most adolescents released from the 
rehabilitation centre tend to experience relapse and be readmitted at rehabilitation centres (Department of Prison Malaysia, 2019). Furthermore, in 2017, property crimes recorded 77,802 cases, while violent crimes recorded a total of 21,366 cases ( $\mathrm{Ng}$ et al., 2020). The statistics also show that among $10 \%$ and $40 \%$ of incarcerated adolescents previously in rehabilitation care have been unemployed when being contacted, and many of them had problems maintaining stable employment (Altschuler et al., 2004). They encounter difficulties in various issues upon reintegrating into society, such as unemployment which leads and contributes to homelessness (Jasni et al., 2019). According to Shong et al. (2018), they found out that more than a third of youth formerly in care reported a perceived lack of preparedness in several skill areas. Thus, these incarcerated adolescents who have involved in repeated and persistent criminal offences can be considered inmates at risk. This article seeks to understand this phenomenon by focusing on the readiness of the adolescents with conducts issues to be reintegrated with community. Also, this paper aims at proposing future directions for research activities in attending to this issue.

\section{Background Information of Tunas Bakti School (STB)}

The Tunas Bakti School is an institution for behavioural rehabilitation (SWD, 2010b). It was launched under Section 65 (1) of the Child Act of 2001 for the rehabilitation and care of children who were uncontrolled and involved in crimes such as robbery, illicit drug use, and weapons possession (SWD, 2010b). Besides, according to the Child Act of 2001 (SWD, 2010b), children are placed in the school after being ordered by the Children's Court for some other reasons. The school's primary aim is to educate and teach the children with positive attitudes, assist them to develop a strong personality, and equip them with skills that could enable them to live independently within the community.

The rehabilitation period is approximately three years, but the children can be discharged after a year if approved by the Board of Visitors (SWD, 2010b). Furthermore, the Tunas Bakti School offers services such as rehabilitation and care, counselling, religious and moral education, academic classes (computer and reading programmes), vocational training like electrical and mechanical workshops, and outdoor activities (SWD, 2010b).

\section{Aetiology}

Previous research has been conducted to understand the conduct issues among adolescents from various perspectives. One of them is the ecological factors that could lead to the involvement of adolescents in criminal activities. For instants, previous research had studied the inefficiency of coping skills, low socioeconomic status (SES), poor community structure, poor parenting practices and also low level of resilience and emotional control in relation to adolescents' criminal activities (Buehler, 2006; Tolan, Gorman-Smith \& Henry, 2003). Similarly, earlier studies have also indicated that the prevalence of this adolescent delinquency seems to be connected to the combination of psychological changes during adolescence, as in for the need for autonomy and the decrease of adult monitoring experienced by them (Schulenberg \& Zarrett, 2006). The extent of these factors is forced into an accelerated involvement of adolescents in incarceration should be taken into consideration. Therefore, to address these challenges, a more thorough approach is needed to understand how well the incarcerated adolescents are ready to face the obstacles and interact with society once they are out of rehabilitation care. The readiness for independent 
living and good competency skills and moral values is vital to reflect on those factors that lead to juvenile crime involvement (Moses \& Villodas, 2017).

The readiness for independent living among these incarcerated adolescents is defined as the ability to serve their needs, feeling comfortable with themselves, and satisfy their relationships with significant others. Adolescents set in imprisonment confront high dangers impediments when transitioning to adulthood due to their individual and natural circumstances (Gagnon et al., 2012). Numerous analysts have troublesome on how these youths alter their lives after a period of incarceration. Despite that, there are plenty of preceding studies shows that the incarcerated adolescent faces a few demanding situations of their recuperation manner after the incarceration length of dealing with phrases of educational, behavioural, intellectual fitness problems, poorer social relationships with family, society popularity and a vulnerable self-resiliency (Zeira\&Benbenishty, 2011). Ready to know when they are being discharged, they confront prompt challenges as they endeavour to reintegrate into the community where they go up against critical obstructions to victory.

Children in Malaysia may be placed in institutions as a form of alternative care in the context of immigration or within the criminal justice system. The negative impacts of institutionalisation on children's development and rights are well documented; according to international standards, deprivation of liberty should be the last resort in the case of children, and institutional care as a form of alternative care is also considered harmful to children. This is because, placing adolescents in rehabilitation centres without proper guidance and effective implementations of support, may wear them out and overwhelm their ability to cope with the existing situation (Rickwood et al., 2007; Zwaanswijk et al., 2003).

Besides, the latest update concerning incarcerated adolescents in Malaysia shows the number of children involved in repeated crime has improved by $13.3 \%$ as compared to the previous year, which was about 675 cases in 2018 and 585 cases in 2019, respectively (Department of Statistics Malaysia, 2020). However, the total number of cases indicates that the problem remains a stable threat and is still alarming.

Out there, these incarcerated adolescents do face insecurity, limited job opportunities and lack of essential skills required. By far, adequate and appropriate knowledge revolving around the crimes these adolescents had committed is not taken strictly under consideration. Limited knowledge about the implications is conceptualised, along with the inability of the adolescents to explain the possible consequences of their criminal behaviours (Smetana, 2017). All the stated unavailability is due to the different nature of cases exist as limited approach is being implemented (Ongley \& Crothers, 2013). The term 'limited approach' is explained as all incarcerated adolescents do come from various backgrounds which reflects the situation of cases they commit even when the cases committed might be the same but the nature of cases is different. For instance, the intervention programs implemented at the approved school in Malaysia do not emphasise each individual's unique pattern of characteristics (Newton, 2018). Additionally, the existing intervention programs are mostly based on 'one for all' orientation, as it is linked to either the positive or negative development of adolescents' psychological and behavioural well-being (Reisz et al., 2013). Also, even if the orientation may correlate, the outcome towards readiness will be reflected into various divergent views as these incarcerated adolescents have to go through the same intervention process regardless of their different cases and background (Benbenishty\& Magnus, 2008). 
The adolescent's vulnerabilities concerning the unconducive social environment they have to deal with interrelating with their relapse cases put them at higher risk of committing a crime once again.

This practice reflects the nature of every single criminal case. The aetiology or the contexts differ even though the criminal behaviours are the same between one adolescent and another. Some of them might be clinically diagnosed in this vein, but others may be viewed as merely responding to the adversities in their life experiences (Marsh \& Evans, 2009). Yet, little is known on how well incarcerated adolescents are equipped with relevant knowledge and skills to ensure their readiness to integrate with the outside social world upon their release from the approved schools. Given that, their readiness to cope and adapt with their lives upon their release remains elusive. In this light, despite all the existing intervention programs at the rehabilitation centres, the aim to enhance and increase therapeutic techniques such as increasing positive behaviours and improving interpersonal skills shows significant decline along the process (Smeets, 2014). It has also been suggested by UNICEF (2020) to improve data and understanding of institutionalisation, including the drivers and circumstances of placement in rehabilitation centres.

As noted earlier, adolescents had become increasingly involved in much problematic behaviour (Clinkinbeard et al., 2012). It really a shame, but it is the reality in our nation. Be that because it may, there's no specific pointer that can be utilised to evaluate and characterise this issue. As in this, individual components are explored to comprehend the exact issues standing up to have an independent living upon release. Although an array of research has successfully linked different resources with the affected adolescents' recovery process in Malaysia, a limited number have attempted to explore the issue from adolescents' perspectives on how well they cope.

\section{Examination of Factors towards Readiness for Independent Living}

Previous research found that, as incarcerated adolescents faced multiple issues in their lives that contextualized they are offending, they were aware that if their issues remained unresolved, it would become a challenge in their recovery process on release (Daud, 2017). Therefore, the incarcerated adolescents face a conflict, either to change or to remain unchanged. Their primary concern was that no matter how they have changed, they would be perceived as bad people (Daud, 2017). Yet, the rehabilitation centers usually have no control over the highlighted external factors, thus leaving the adolescents surviving by themselves in the challenging context upon release. On the other hand, while other relevant governmental and private agencies focus on mitigating or eliminating the external risks, in this present study, we believe that the focus should also be directed towards preparing the affected adolescents mentally and emotionally in facing the adversity of their external world. This idea is associated with the incarcerated adolescents' readiness for their recovery process and their reintegration into their social environments after being released from the approved schools.

The readiness for independent living among these incarcerated adolescents depends mainly upon the ability to provide for their needs, feel comfortable with themselves, and be satisfied with relationships with significant others (Yates \& Grey, 2012). A finding states that 152 adolescents face a significant problem in the readiness to leave the centre. For instance, only 
$65 \%$ were expected to be able to search for a job effectively, and less than half of the adolescents were assessed as being able to look for accommodation or avoid associating with peers who may have a negative influence, in which we can conclude as they do have good coping resources. Each year, more than 20,000 youth exit the care system with the expectation that they will be able to live self-sufficiently (GAO, 1999). However, limited research is available about the post-discharge functioning of these incarcerated adolescents emancipated from foster care.

On the other hand, incarceration seen in adolescents is correlated with a lack of coping resources (Gergelis et al., 2016). These incarcerated adolescents are not paralyzed with fear of leaving care, expect to cope successfully, and are energized to re-enter the community for independent living. Coping is defined as the process of executing a response to a stressor, where stress is viewed as the experience of encountering relevant difficulties in one's goalrelated efforts (Carver \& Connor-Smith, 2010). It is also known as the extent to which an individual believes that his/her needs for support, information, and feedback are fulfilled which also plays a major role in this study. It is a vital element among incarcerated adolescents' appraisal of and subsequent readiness for independent living later on (Swindle et al., 2002).

Concretely, a coping response of an inmate is generally considered adaptive when it leads to a greater likelihood of attaining desired goals (Macey et al., 2008). However, extreme gaps between adolescents' coping resources and actual capabilities may pose severe threats to the adolescents' ability to deal with the challenges of leaving care, as these challenges are left unacknowledged, and therefore no coping strategies are constructed (Abrams, 2012). Furthermore, due to the lack of awareness of the limitations of their coping resources, adolescents' willingness to engage in life skills and re-entry to the external world are also hindered (Wrosch et al., 2003). Hence, a critical initial step of coping resources should be instilled to encourage incarcerated adolescents' beliefs in their abilities, but at the same time to assist them to delineate the challenges lying ahead accurately, form concrete strategies to overcome them, and address the gaps between their perceived and actual level of readiness for an independent living.

\section{Theoretical Underpinnings}

When viewing human development across the life cycle, it is important to move from a general overview of the pattern of development to an explanation of the specific processes at each life stage. A theory provides a valuable tool for organizing ideas and information. According to Newman \& Newman (1976), a theory of human development must account for both stability and change in the individual. Theories that focus on changing processes generally ignore individual continuity, while those that focus on individual continuity generally ignore the process of change (Newman \& Newman, 1979).

The present investigation is based upon the Bronfenbrenner's Ecological Systems Theory of Development (Bronfenbrenner, 1979). The Bronfenbrenner's Ecological Systems Theory of Development posed in this research gives prominence to the environment and divided the individual's environment into nested and interrelated systems such as the microsystem, mesosystem, exosystem, macrosystem and chronosystem. As the individual themselves goes through all these ups and downs throughout and after their rehabilitation period, coping 
resources do take place within all the system and implement it in a certain way to cope in a right manner. These processes do take place and vary over time throughout the incarcerated adolescents. For instant, during the rehabilitation period and after the period, it is not the same anymore. Time is construed at various levels of the ecological system. This is called the chronosystem, which concludes all this progress upon the readiness for independent living among these incarcerated adolescents.

According to this theory, development is hypothesized to be the joint product of four defining properties: the person, context, process, and time. In this case, individuals have the persistent fear that they are losing their hold on themselves and on their future. However, with proper coping resources provided, these incarcerated adolescents can bump back into the track. It is important to know the defined factors that play an important role in independent living for these incarcerated adolescents. The task of bringing together the many elements of one's experience into a coordinated, clear self-definition is difficult and time-consuming, and one undoubtedly experiences temporary periods of confusion and depression during their incarceration period. The adolescent is likely to experience moments of self-preoccupation, isolation and discouragement as the diverse pieces of the puzzle are shifted and reorganized into the total picture.

According to the Bronfenbrenner's Ecological Systems Theory of Development, we can expect that the development of incarcerated adolescents varies between individuals and, more specifically, it is particularly dependent on the external aspects. In their efforts to define themselves, they must consider the bonds that have been built between themselves and others in the past, as well as the direction that they hope to be able to take in the future by having a balance coping resource throughout their phase of life. Thus, the theory provides insight into how these incarcerated adolescents engaged in activities by having a positive and well-balanced coping resource on how other aspects of life affect their development more broadly upon having an independent life.

\section{Future Direction}

This article seeks to analyse the strengths and limitations of the existing intervention programs at approved schools in Malaysia. Also, factors contributing to incarcerated adolescents' readiness to reintegrate with society and to live independently, namely, coping resources of his/her needs of support, information, and feedback to delineate the challenges lying ahead, are scrutinised and proposed to improve the existing practices. Based on this study, practitioners and policy makers may consider those measurements when emphasising recovery process and their reintegration into their social environments to improve and engage potential defensive components and diminish possible risk components that put this incarcerated adolescents at risk.

For effective enforcement, predictive factors need to be understood in the context of incarcerated adolescents' position, goals, and future ideas about pathways towards readiness within their perspectives. Nevertheless, their voices are notably lacking in the existing intervention programs as they viewed it as a trap, leading them down an inevitable pathway back to incarceration. Considering adolescents' incarceration is one of the most pressing social problems felt throughout society, efficacious interventions are a priority. Unfortunately, many gaps remain unacknowledged, as numerous studies investigating readiness for independent living aspect is mainly upon the Western contexts; which weakens 
the endpoint of intervening against juvenile incarceration in Asian context. Perhaps, this study built upon and enhance additional body of knowledge by examining these relationships in an Asian context. Although more studies are needed to undergird relationships between these variables in East Malaysia and other Asian countries to enable better generalizability of findings among Asian populations, this study gives a preliminary basis for adding to the current body of research.Thus, this paper would underpin the research and interventions in the future as it focused on the adolescents' stability and long-term support aspects consistent with their needs and capabilities in an Asian context.

To address and narrow these gaps, the vitality of future research to improve the existing knowledge and to create new insight is crucial to elucidate the perspectives of incarcerated adolescents' on the readiness for independent living. It is necessary to come out with research that attempts to understand the experience and the needs of the adolescents themselves. It is essential so that the proposed interventions are reflective enough to mitigate and eliminate the external risks in preparing the adolescents to face the adversity of their external world. Prior to that, as explained earlier in relation to the theory of human development, future research must account for both stability and change in the individual by giving prominence to the interrelated factors surrounding the adolescent solely. Thus, these factors are vital because they will form a basis in developing intervention programs that bring out the best approach for incarcerated adolescents by knowing them better individually in every aspect. Also, the benefits of this recommendation will provide a fundamental understanding on the readiness for independent living among incarcerated adolescents in Malaysia context which can be utilize as a source of output for the society to provide supportive environment for these incarcerated adolescents. Last but not least, a new model should be developed that is unique to the Malaysian adolescents to improve and engage potential components for the readiness for independent living.

\section{Conclusion}

Adolescents set in imprisonment confront high dangers impediments when transitioning to adulthood due to their individual and natural circumstances (Gagnon et al., 2012). Ready to know when they are being discharged, they confront prompt challenges as they endeavour to reintegrate into the community where they go up against critical obstructions to victory. Often, nothing is done to eliminate the contextual factors leading to delinquent and criminal acts, and this, in large part, contributes to the lack of treatment effectiveness seen to date. In addition, the relative paucity of research and attention paid to this vulnerable population may be a factor impeding their well-being. Ultimately, these factors are essential because they will form a basis in developing intervention programs in the future applicable to variables across social networks contributing to adolescents' readiness to fit into the spectrum of specific needs, strengths, and weaknesses as a whole. Thus, along with reducing the gaps effectively, this serious problem of conduct issues among adolescents should be addressed strictly. In short, this present article urges to undermine solutions and interventions in order to eliminate the challenges lying ahead for the readiness for independent living among the incarcerated adolescents.

\section{References}

Abrams, D. S. (2012). "Estimating the Deterrent Effect of Incarceration Using Sentencing Enhancements." American Economic Journal: Applied Economics, 4 (4): 32-56. 
Altschuler, D. M., Brash, R. (2004). Adolescent and Teenage Offenders Confronting the Challenges and Opportunities of Reentry. Youth Violence and Juvenile Justice.;2(1):7287.

Bacikova-Sleskova, M., Benka, J., \& Orosova, O. (2014). Parental employment status and adolescents' health: The role of financial situation, parent-adolescent relationship and adolescents' resilience. Psychology \& Health, 30(4), 400-422.

Benbenishty, R., \& Magnus, A. (2008). A bridge to care leavers without families: Evaluation of an intervention program. Hebrew MifgashLeavodaChinoochit-Sozialit, 28, 45-84.

Bronfenbrenner, U. (1979). The ecology of human development: Experiments by nature and design. Cambridge, Mass: Harvard University Press.

Buehler, C. (2006). Parents and Peers in Relation to Early Adolescent Problem Behavior. Journal of Marriage and Family, 68(1), 109-124.

Carver, C. S., \& Connor-Smith, J. (2010). Personality and coping. Annual Review of Psychology, 61, 679-704.

Clinkinbeard, S. S., \& Zohra, T. (2012). Expectations, fears, and strategies: Juvenile offender thoughts on a future outside of incarceration. Youth \& Society, 44, 236-257.

Daud, M. D. (2017). Globalisation in the Malaysian context: The experience of Malay adolescents with 'conduct disorders' (Unpublished doctoral dissertation). Massey University, New Zealand.

Department of Statistics Malaysia. (2016). Children statistics, Malaysia 2016.

Department of Prison Malaysia. (2019). Rehabilitate Child and Young Offenders, 2019.

Gagnon, J. C., Houchins, D. E., \& Murphy, K. M. (2012). Current juvenile corrections professional development practices and future directions. Teacher Education and Special Education, 35, 333-344.

Gergelis, K., Kole, J., \& Lowenhaupt, E. (2016). Health care needs of incarcerated adolescents. Rhode Island Medical Journal, 99(9), 24-26.

Jasni, M., Abu Bakar Ah, S., MohdYusoff, J., Shahid, K., Omar, N., \& Azman, Z. (2019). Family refusal as a contributing factor to the homelessness problem among former prisoners in malaysia. Sarjana, 34(1), 23-37.

Marsh, S. C., \& Evans, W. P. (2009). Youth perspectives of their relationships with staff in juvenile correction settings and perceived likelihood of success. Youth Violence and Juvenile Justice, 7(1), 46-67.

Mayock, P. (2008) Young people's homeless pathways and the offender-victimisation nexus. In D. Downey (Ed) Perspectives on Irish Homelessness: Past, Present and Future. Dublin: The Homeless Agency. pp. 76-86.

McCaskill, J. W., \& Lakey, B. (2000). Perceived Support, Social Undermining, and Emotion: Idiosyncratic and Shared Perspectives of Adolescents and their Families. Personality and Social Psychology Bulletin. 26(7), 820-832.

Moses, J. O., \& Villodas, M. T. (2017). The potential protective role of peer relationships on school engagement in at-risk adolescents. Journal of Youth and Adolescence, 46(11), 2255-2272.

Newman, B. M., \& Newman, P. R. (1979). An introduction to the psychology of adolescence. Homewood, IL: Dorsey Press, 19(1), 541.

Newton. (2018), The Impact of Vocational Education and Training Programs on Recidivism: A Systematic Review of Current Experimental Evidence. International Journal of Offender Therapy and Comparative Criminology, Vol. 62(1) 187-207. 
Ng, E. E., Daud, M. N., Arshat, Z., \& Azam, N. D. (2020). Social Preference towards Reactive Aggression among Justice-Involved Adolescents in Malaysia. International Journal of Academic Research in Business and Social Sciences, 10(7), 265-279.

Reisz, Z., Boudreaux, M. J., \& Ozer, D. J. (2013). Personality traits and the prediction of personal goals. Personality and Individual Differences, 55(6), 699-704.

Schulenberg, J. E., \& Zarrett, N. R. (2006). Mental Health During Emerging Adulthood: Continuity and Discontinuity in Courses, Causes, and Functions. American Psychological Association, 135-172.

Smetana, J. G. (2017). Current research on parenting styles, opinions, and beliefs. Current Opinions in Psychology, 15, 19-25.

Stein, M. (2006a). Young people aging out of care: The poverty of theory. Children and Youth Services Review, 28 (4), 422-435.

Stein, M. (2006b). Research review: Young people leaving care. Child and Family Social Work, 11(3), 273-279.

Stein, M. (2008). Resilience and young people leaving care. Child Care in Practice, 14(1): 3544.

Swindle, R., Heller, K., \&Frank, M. (2002). Differentiating the effects of positive and negative social transactions in HIV illness. Journal of Community Psychology;28,35-50.

Tolan, P. H., Gorman-Smith, D., \& Henry, D. B. (2003). The developmental ecology of urban males' youth violence. Developmental Psychology, 39(2), 274-291.

UNICEF. (2013).The State of the World's Children 2013, Children with Disabilities.

Wade, J. (2008). The Ties that Bind: Support from Birth Families and Substitute Families for Young People Leaving Care.British Journal of Social Work, 38(1), 39 - 54.

Wrosch, C., Scheier, M. F., Carver, C. S., \& Schulz, R. (2003). Theimportance of goal disengagement in adaptive self-regulation:When giving up is beneficial. Self and Identity2, 1-20.

Yates, T. M., \& Grey, I. K. (2012). Adapting to aging out: Profiles of risk and resilience among emancipated foster youth. Development and Psychopathology, 24, 475-492.

Zeira, A., \& Benbenishty, R. (2011). Readiness for independent living of adolescents in youth villages in Israel. Children and Youth Services Review, 33, 2461-2468. 